\title{
Sistema y método para fijar las tarifas de tasas y las contribuciones
}

\author{
César Augusto Romero-Molina ${ }^{\star}$, Ligia Colmenares-Jácome ${ }^{\star *}$, Andrea Catalina Murillo-Olarte $^{\star * *}$
}

* Posdoctorado de la Universidad de Castilla-La Mancha. Doctor en Derecho de la Universidad San Pablo-CEu. Director del Centro de Investigaciones Sociojurídicas (cis) de la Facultad de Derecho de la Universidad Cooperativa de Colombia, sede Bucaramanga, Colombia.

Correo electrónico: cesaraugusto.romero@gmail.com

** Abogada de la Universidad Cooperativa de Colombia, sede Bucaramanga. Asesora jurídica de la Alcaldía de Girón, Santander, Colombia.

Correo electrónico: ligia_colmenaresjacome@hotmail. com

*** Abogada de la Universidad Cooperativa de Colombia, sede Bucaramanga. Asesora jurídica del Hospital Universitario de Santander, Colombia.

Correo electrónico: catamuol@hotmail.com

Recibido: 14 de diciembre del 2012 Aprobado: 17 de abril del 2013

\section{Cómo citar este artículo:}

César Augusto Romero-Molina, Ligia Colmenares-Jácome \& Andrea Catalina Murillo-Olarte. Sistema y método para fijar las tarifas de tasas y las contribuciones. DIXI. Junio 2013. At. 55.

\section{Resumen}

Este artículo surge como producto de la investigación terminada titulada "Sistema y método para definir el costo de las tarifas de las tasas y las contribuciones", llevada a cabo en el 2012 en la Universidad Cooperativa de Colombia, sede Bucaramanga. En ella se analizaron las diferentes interpretaciones realizadas por la Corte Constitucional sobre la forma de establecer el sistema y método para fijar el monto de las tasas y las contribuciones y la inseguridad que ha generado el artículo 338 constitucional al dejar un vacío interpretativo sobre quiénes son los competentes para establecerlos. Para dar respuesta al planteamiento hecho, se hace análisis jurisprudencial de 1993 al 2012 y se compara con el sistema y método usado en la legislación española.

Palabras clave: constitución, contribuciones, sistema y método, tasas, tributo.

\section{System and Method to Define the Cost of Tax and Contribution Rates}

\begin{abstract}
This article arises from research entitled "System and Method to Define the Cost of Tax and Contribution Rates", carried out at the Bucaramanga campus of the Universidad Cooperativa de Colombia, Bucaramanga campus. Different interpretations by the Constitutional Court on how the system and method for determining taxes and contributions rates operates and the insecurity generated by Article 338 of the Colombian Constitution that creates an interpretative vacuum regarding the question of who has the jurisdiction to establish these taxes and rates were analyzed. In order to give an answer to this question, a jurisprudential analysis from 1993 until 2012 is made and compared with the system and method used in the Spanish legislation.
\end{abstract}

Keywords: constitution, contributions, system and method, rates, taxes.

\section{Sistema E MÉTOdo PARA FIXAR AS TARIFAS DE TAXAS E DAS CONTRIBUiÇÕes}

\section{Resumo}

Este artigo surge como produto da pesquisa terminada intitulada "Sistema e método para definir o custo das tarifas das taxas e das contribuições”, realizada em 2012, na Universidade Cooperativa da Colômbia, sede Bucaramanga. Analisaram-se as diferentes interpretações realizadas pela Corte Constitucional sobre a forma de estabelecer o sistema e método para fixar o montante das taxas e das contribuições e a insegurança que o artigo 338 constitucional vem gerando ao deixar um vazio interpretativo sobre quem são os competentes para estabelecê-los. Para dar resposta à proposição feita, faz-se análise jurisprudencial de 1993 a 2012 e compara-se com o sistema e método usado na legislação espanhola.

Palavras-chave: constituição, contribuições, sistema e método, taxas, tributo. 


\section{INTRODUCCIÓN}

A lo largo de la historia de la humanidad las obligaciones tributarias han sido inherentes al hombre y han formado parte de su evolución, tornándose religiosas, gubernamentales y hasta despóticas. En las épocas primitivas se sacrificaba a un ser humano en honor a un dios por los favores o beneficios recibidos. Posteriormente, en las diversas castas familiares de reyes y monarcas, se imponían los tributos a la población de bajos recursos para el sostenimiento del reino, para financiar las guerras o por simple capricho de los gobernantes; los tributos se imponían a su forma y acomodo, y en diversas oportunidades su pago se tornaba violento contra el pueblo, llegando incluso a esclavizarlos debido a la imposibilidad de sufragarlos.

La presente investigación tiene en cuenta que el artículo 338 Superior - relacionado con la competencia que tienen los entes de elección popular o las autoridades administrativas para establecer el sistema y método para fijar el costo de las tasas y contribuciones- es ambiguo, generando con ello un vacío interpretativo por parte del constituyente de 1991.

De acuerdo con lo anterior, para dar respuesta al vacío que hemos planteado, haremos un análisis jurisprudencial desde 1993 hasta el 2012, con el fin de resolver las inquietudes presentadas y que fueron el motivo para la realización del presente artículo.

\section{Sistema y MÉTODO PARA FIJAR EL COSTO DE LAS TASAS Y LAS CONTRIBUCIONES EN OTRAS LEGISLACIONES}

\section{A. Sistema español}

La Constitución Española [Const.]. Art. 157.1 b) (España) establece que las comunidades autónomas pueden recaudar sus recursos a través de los impuestos, tasas y contribuciones, con el fin de autofinanciar sus propios proyectos.

\section{Las tasas}

La Ley 58 del 2003. Ley General Tributaria. Diciembre 17 del 2003, define las tasas como aquella utilización privativa en la que se tiene un aprovechamiento es- pecial de quien lo solicita, surge como consecuencia de la solicitud realizada por el contribuyente y este le cause un beneficio. El titular del servicio es el Estado y estos deben ser regidos por las normas de Derecho Administrativo. ${ }^{1}$

Asimismo el artículo 2.2 en su letra g) establece dos formas de cancelación de la tasa: la primera consiste en la utilización privativa o el aprovechamiento especial del dominio público y la segunda corresponde a la prestación de servicios en la realización de actividades en régimen de derecho público. ${ }^{2}$

Según el texto refundido, las tasas estatales fiscales se dividen en dos grupos:

\section{- 1.1. Tasas reguladas:}

- Canon de superficie de minas. Se cancela por el otorgamiento de permisos de investigaciones o concesiones de explotación minera.

- Tasas por cancelación en actuaciones y servicios en materias marítima, aérea y registro de especialidades farmacéuticas.

- Tarifa de rifas y apuestas. Se fija un porcentaje de acuerdo con el valor de los boletos o del premio.

\section{- 1.2. Tasas en régimen especial:}

- Se exigen por los servicios de correo y telecomunicaciones.

1 Ley 58 del 2003. Ley General Tributaria. Diciembre 17 del 2003. (España). Art. 2.2. a) "[...] los tributos cuyo hecho imponible consisten en la utilización privativa o aprovechamiento especial de dominio público, la prestación de servicios o la realización de actividades en régimen de derecho público que se refieran, afecten o beneficien de modo particular al obligado tributario, cuando los servicios o actividades no sean de solicitud o recepción voluntaria para los obligados tributarios o no se presten o realicen por el sector privado".

2 Ernesto Eseverri. Derecho tributario. Parte general. Pág. 213. Editorial Tirant Lo Blanch. (2008). "[...] las normas de derecho administrativo precisan qué es dominio público, automáticamente, si cualquier particular pretende hacer uso de él en provecho propio y lo utiliza en su exclusivo beneficio, deberá satisfacer la tasa correspondiente por tal motivo [...] Los montes son bienes de dominio público, cuando una parte de ellos se acota como zona vedada de caza para su aprovechamiento especial por quienes se asocian a tales efectos, tienen que pagar la correspondiente tasa por ese concepto $[. .$.$] la prestación del servicio público ni tiene que beneficiar a$ todos, ni siempre tiene porqué derivarse de un beneficio para quien lo recibe, pues basta con que de alguna manera le afecte o a él se refiera para quedar obligado al pago de la tasa. Sucede así con las tasas judiciales que deben satisfacer determinadas personas jurídicas por pleitear en los juzgados y tribunales, es posible que la sentencia pronunciada les resulte desfavorable, sin perjuicio de lo cual, al interponer el recurso deben satisfacer la tasa judicial correspondiente porque se trata de sujetos a los que se va a referir ese pronunciamiento o de algún modo les afecta la resolución dictada. 
- Por servicios del cónsul español en el extranjero.

- Por los derechos de las delegaciones de industria. Se paga por servicios prestados por estas delegaciones.

\section{Las contribuciones}

La Ley General Tributaria en su artículo 2.2. b) define las contribuciones como aquellos "[...] tributos cuyo hecho imponible consiste en la obtención por el obligado tributario de un beneficio o aumento de valor de sus bienes como consecuencia de la realización de obras públicas o del establecimiento o ampliación de servicios públicos". ${ }^{3}$ El sujeto recibe un beneficio con la realización de una obra por la autoridad administrativa, el cual puede consistir en el aumento del valor catastral. Esta clase de tributo es considerado como una imposición municipal.

El cobro de las contribuciones se realiza de la siguiente manera: mediante un Acuerdo de Imposición Provisional el ayuntamiento aprueba la obra que se requiere realizar, y una vez terminada se debe cancelar. ${ }^{4}$

Los acuerdos de ordenación e imposición provisional deben contener o estipular el costo de las obras a realizar y las respectivas liquidaciones, en las cuales se establecen los pagos correspondientes que deben cancelar los contribuyentes que se beneficien con dichas obras. Las Comunidades Autónomas y las entidades locales son autónomas en el manejo e incluso puede realizar convenios con la administración para realizar el manejo y recaudo de los recursos. ${ }^{5}$ En esta imposición tiene especial consonancia el principio de territorialidad, pues sólo quedan sujeto a dicho pago quienes se beneficien con dichas obras.

\section{B. Sistema colombiano}

En el sistema impositivo colombiano la doctrina y la jurisprudencia no han podido unificar criterios respecto de la definición y la naturaleza jurídica de las tasas y las contribuciones, ya que la tasa representa la equivalencia entre el servicio prestado por el Estado y el beneficio que se presta en las contribuciones.

\footnotetext{
3 Ver Ley 58 del 2003. Ley General Tributaria. Diciembre 17 del 2003. (España). Art. 2.2. b).

4 Ver id. Cita 5. Pág. 245.

5 Ver Félix de Luis Díaz de Monasterio \& Francisco Uría Fernández. El sistema fiscal español y las entidades y operaciones financieras. Estudios en homenaje a Enrique Piñel. Pág. 76. Editorial La Ley. (2006).
}

\section{Las tasas}

El concepto de tasa ha sido establecido por la doctrina, en la cual se establece que el hecho generador corresponde a la actividad realizada por parte del Estado y realizada bajo su potestad ${ }^{6}$ y soberanía, y la cual se encuentra directamente relacionada con el contribuyente. $^{7}$

La Corte Constitucional ha definido la tasa ${ }^{8}$ como una prestación pecuniaria en la que el sujeto pasivo de la obligación debe cancelar por los servicios que presta el Estado y cuyo dinero recaudado es destinado para financiar o cubrir los gastos ocasionados por dicha prestación. Una característica importante es la voluntariedad que tiene el sujeto obligado a cancelar dicha obligación por hacer uso del servicio. ${ }^{9}$ Aunque para algunos doctrinantes como Belsunce la tasa es "obligatoria", ${ }^{10}$ este autor manifiesta que el sujeto se encuentra en la obligación de cancelar una vez haya utilizado el servicio. Un sector de la doctrina establece que la tasa se encuentra inmersa en los precios públicos, al estar establecidos en una ley que los regule, ya que la retribución que se cancela constituye la prestación de un servicio público, pero debemos tener en cuenta aunque

6 Ver Héctor B. Villegas. Curso de finanzas, derecho financiero y tributario. Vol. II. Pág. 90. Editorial Depalma. (1979). "Es un tributo cuyo hecho generador está integrado con una actividad del Estado divisible e inherente a su soberanía, hallándose esa actividad relacionada directamente con el contribuyente".

7 Ver Mauricio Plazas Vega. Derecho de la hacienda pública y derecho tributario. Las ideas políticas de la hacienda pública. Pág. 870. Editorial Temis. (2000).

8 Ver Corte Constitucional de Colombia. Sentencia C-1179 del 2001. (M.P. Jaime Córdoba Triviño: Noviembre 8 del 2001). "Las tasas son prestaciones pecuniarias que constituyen remuneraciones de los particulares por los servicios prestados por el Estado en desarrollo de su actividad, sus tarifas son fijadas por autoridades administrativas, ellas no necesariamente comprenden el valor total del servicio prestado, hacen parte del presupuesto, se someten a control fiscal, su cuantía es proporcional al costo del servicio y son administrados por el Estado".

9 Ver José Luis Zavala Ortiz. Manual de derecho tributario. Pág. 11. Thomas Reuters. (2010).

10 Ver Horacio Belsunce García. Temas de derecho tributario. Pág. 214-216. Editorial Abeledo Perrot. (1982). "La tasa como tributo es una contribución obligatoria, de demanda coactiva, porque el rendimiento del servicio es obligatorio como condición para ejercer ciertos actos o derechos. Por ejemplo, sin la inscripción en el registro de propiedad no se puede ejercer el derecho de prelación que corresponde al crédito hipotecario; sin la inscripción en el registro de propiedad intelectual no se puede ejercer el derecho de autor [...] A quienes consideran que la tasa es voluntaria porque no hay obligación de requerir el servicio, contestaría que también el impuesto sería voluntario porque no hay obligación de ser propietario y tener que pagar el impuesto inmobiliario; tampoco hay obligación de ejercer actividades rentables para tener que pagar el impuesto a la renta o ganancia. 
ellos han sido creados por la ley, ella regula el mercado, mas no los crea. ${ }^{11}$

La jurisprudencia constitucional ha establecido unos elementos esenciales para que se configure la tasa, los cuales consisten en los siguientes:

(i) prestación tributaria establecida por norma legal o con fundamento en ella; (ii) titularidad del Estado, directa o indirecta; (iii) cuantificación referenciada al costo del servicio o del bien de que se trate; (iv) relación directa del contribuyente con una actividad de interés público o un bien de dominio público, a través de su solicitud. ${ }^{12}$

\section{Las contribuciones}

La Corte Constitucional define las contribuciones como aquellas prestaciones que se establecen a un grupo o sector de la población y cuyo recaudo es utilizado para su beneficio. ${ }^{13}$ Valdez Costa establece que "una especie tributaria independiente del impuesto y de la tasa está constituido por la actividad del Estado realizada con fines generales, que simultáneamente proporciona una ventaja particular al contribuyente; el destino es necesaria y exclusivamente el financiamiento de esa actividad"14 generando una ventaja al grupo frente a otro sector o grupo de la población.

Las contribuciones han sido dividas en tres grupos: el primero corresponde a la contribución por mejoras, es una contribución creada mediante la Ley 25 de 1921 que inicialmente consistió en un impuesto sobre las propiedades raíces que se beneficien con la ejecución de obras de interés público local, pero mediante el Decreto 1604 de 1966 se le denominó como contribución, debido a

11 Ver id. Cita 8. P. 873: "Es una prestación Tributaria establecida por la ley o con fundamento en la ley, a favor del Estado como titular directo o indirecto, originada por una actividad de interés público o colectivo directamente relacionada con el contribuyente, o por la utilización de un bien de dominio público, que no obstante ser indispensable para él, tiene lugar en virtud de su solicitud, y cuya cuantía tiene como criterio de referencia el costo de la actividad o de la disponibilidad del bien que se trate".

12 Ver Corte Constitucional de Colombia. Sentencia C-134 del 2009. (M.P. Mauricio González Cuervo: Febrero 25 del 2009.)

13 Ver Corte Constitucional de Colombia. Sentencia C-1179 del 2001. (M.P. Jaime Córdoba Triviño: Noviembre 8 del 2001). "[...] gravámenes obligatorios que no tienen el carácter de remuneración de un servicio prestado por el Estado, no afectan a todos los ciudadanos sino únicamente a un grupo económico determinado, tienen una destinación específica en cuanto se utilizan para el beneficio del sector económico que soporta el gravamen, no se someten a las normas de ejecución presupuestal y son administrados por órganos que hacen parte de ese mismo renglón económico".

14 Ver Ramón Valdés Costa. Curso de derecho tributario. Pág. 179. Editorial Temis. (2001). los beneficios que recibe el sujeto obligado a cancelarlo y su pago surge como "consecuencia de una inversión que beneficia a un grupo específico de personas. Cuando el vocablo se utiliza en este sentido, lo usual es hacer referencia a una 'contribución especial'". ${ }^{15}$

El segundo grupo de obligaciones tributarias corresponde a las contribuciones por servicios impuestos, que constituye la prestación de un servicio que beneficia al contribuyente y cuyo recaudo financia dicho servicio. Algunos tratadistas, como Plazas Vega, aducen que las contribuciones por servicios son una modalidad de "préstamos o inversiones forzosas" ${ }^{16}$ por el beneficio de un servicio financiero que no requiere intervención del Estado.

En el tercer grupo están las contribuciones parafiscales que tuvieron sus orígenes mediante la Ley 76 de 1927 - y surgieron como consecuencia de las exportaciones de café- en la cual se estableció la cancelación de 10 centavos por cada saco de 70 kilos, en ese entonces.

Según Duverger podemos catalogar la parafiscalidad como los impuestos corporativos ${ }^{17}$ aunque pone de manifiesto reconocer las tasas y contribuciones y rechazar de plano la triconomía que se defiende en América, y lo que le corresponde a Colombia lo contempla en su artículo 338 Superior.

\section{Sistema y método en la Constitución de 1886}

La Carta Constitucional de 1886 definía a Colombia como república unitaria pero no contemplaba la autonomía de las entidades ni la descentralización administrativa. Esta denominación constitucional tenía

15 Ver Corte Constitucional de Colombia. Sentencia C-155 del 2003. (M.P. Eduardo Montealegre: Febrero 26 del 2003.)

16 Ver id. Cita 8. P. 931: El “préstamo forzoso" es un impuesto, de quienes afirman que es una "cuarta modalidad de tributo" y, naturalmente, de la tesis según el cual no tiene naturaleza tributaria...”

17 Ver Maurice Duverger \& Enrique Bagaria Perpiña. Hacienda pública. Pág. 70. Casa Editorial. (1980). "No solo consisten en su naturaleza tributaria sino que llegan a afirmar que no hay distinción válida entre "las contribuciones parafiscales" y los "impuestos", motivo por el cual resulta viable designar esta modalidad de tributos con el hombre de impuestos corporativos". Igualmente destaca que "[...] las contribuciones de esa naturaleza no pueden compararse con las "tasas administrativas" debido a que, por una parte, el contribuyente no puede negarse al pago ni al beneficio que le reporta la actividad promovida con este medio financiero; y, por otra, la retribución obtenida no es proporcional a la erogación efectuada [...] esta constituida por una serie de impuestos corporativos, percibidos en provecho de instituciones públicas o privadas que tienen el carácter de colectividades [...] impuestos que son para tales colectividades como los impuestos locales para los municipios y provincias". 
unas implicaciones en el ámbito tributario por cuanto en su artículo 43 constitucional disponía "En tiempo de paz solamente el Congreso, las asambleas departamentales y los concejos municipales podrán imponer contribuciones", dejando un vacío jurídico referente al sistema y método y la autoridad competente para establecerlas.

El artículo 10 de la Constitución de 1886 constituía el principio de legalidad, pues el Congreso era la institución competente para crear las leyes y con respecto a los tributos contemplaba que deben estar establecidos previamente en la ley, mientras tanto el artículo 76 en su inciso 13 de la Carta Constitucional de 1886 era contradictorio y confuso a lo que establecía el artículo 10 , pues otorgaba unas facultades extraordinarias para legislar al Ejecutivo (presidente de la República) desbordándose en ese entonces las facultades conferidas. ${ }^{18}$

La competencia territorial que denominaba la Constitución de 1886 es una competencia derivada ${ }^{19}$ para los municipios, pues dependían de las leyes ex-

18 Ver http://repository.urosario.edu.co/bitstream/10336/2144/1/190757 86-2010.pdf. Urias Torres Romero cita a la doctora Lucy Cruz de Quiñónez. En Memoria. Instituto Colombiano de Derecho Tributario. Décimas Jornadas de Derecho Tributario. Principios Constitucionales de Derecho Tributario. Pág. 10. (1989). "En nuestra Constitución [haciendo referencia a la Constitución de 1886], aparte de la protección a la propiedad privada con su función social y la garantía de no confiscatoriedad sancionatoria que más adelante expondremos, no se reconocen límites objetivos o condiciones en la facultad de decretar impuestos, facultad que se reconoce como una característica esencial de la soberanía del Estado.

Las normas actuales que consagran este principio [refiriéndose al principio de legalidad], son el artículo 43, que establece la regla general, el artículo 76, numerales 13, 14 y 22 sobre facultades del Congreso para establecer las rentas nacionales, decretar impuestos extraordinarios o señalar pautas sobre gravámenes arancelarios, el artículo 79 , sobre iniciativa gubernamental o del legislador en materias impositivas, el 120, numeral 22, sobre facultades del Presidente sobre aranceles y tarifas aduaneras. En materia de impuestos departamentales y municipales. La Constitución reconoce potestad normativa subordinada a la Ley, a los entes de elección popular dentro de sus respectivas jurisdicciones, según se desprende de los artículos 5º 191 y 197, así como del 183 y 187 numeral $70^{\circ}$.

19 Ver Consejo de Estado. Sala de lo Contencioso-Administrativo. Sección Cuarta. Expediente 16544. (C.P. Martha Teresa Briceño de Valencia: Julio 9 del 2009). "En efecto, respecto de la competencia territorial en temas fiscales, bajo la vigencia de la Constitución de 1886, esta Corporación ha sostenido que "de conformidad con la competencia descrita en los artículos 191 y 197 de la misma Carta, la jurisprudencia de la Corte Suprema de Justicia (oct. 1\%/87, exp. No 1662, Dr. Jesús Vallejo Mejía) y del Consejo de Estado (entre otras, la de fecha 8 de marzo de 1991, exp. 2585 C.P. Dr. Carmelo Martínez Conn), señalaron que esas Corporaciones en la órbita de sus respectivas competencias, tenían la facultad derivada, es decir, requerían previamente de la autorización legal expresa. De lo anterior se advierte que en la Constitución de 1886 la facultad impositiva de los municipios era derivada y, por tanto, no era autónoma, pues aquella estaba supeditada a lo dispuesto en las leyes expedidas por el Congreso". pedidas por el Congreso; "las Ordenanzas de las asambleas eran ejecutivas y obligatorias mientras no fueran suspendidas por el gobernador o por una autoridad judicial", tal y como lo ilustra el artículo 191 ibídem. Igualmente las asambleas departamentales tenían facultades reguladoras de creación de contribuciones en tiempos en paz, siempre y cuando siguieran los preceptos establecidos en la Carta Constitucional y las leyes.

Durante la vigencia de la Constitución de 1886 se excedieron algunas atribuciones en materia tributaria conferidas al Ejecutivo (presidente de la República) en los estados de excepción, pues en ese momento no existía norma alguna que pusiera límites a dicho poder.

\section{Sistema y método en la Constitución de 1991}

Si bien es cierto que con la Constitución de 1991 se lograron llenar algunos vacíos y deficiencias que presentaba la Constitución de 1886, aún se siguen suscitando vacíos y deficiencias en materia y tributaria y tienen que ver con el sistema y método para definir el costo de las tasas y las contribuciones, ya que el constituyente no fue muy claro en definir el sistema y método y la autoridad competente para establecerla.

El artículo $338^{20}$ de la Carta Superior establece que en materia tributaria solamente el Congreso, las asambleas departamentales y los concejos municipales pueden establecer los tributos de acuerdo con la Constitución y la Ley, pero así mismo el artículo $150 \mathrm{nu}$ merales 11 y 12 Superior aduce que el Congreso de la República $^{21}$ es el único ente encargado de crear, modificar y derogar las leyes en Colombia.

20 Ver Constitución Política de Colombia. [Const.] Art. 338. Julio 7 de 1991. (Colombia). "En tiempos de paz, solamente el Congreso, las Asambleas Departamentales y los Concejos Distritales y Municipales podrán imponer contribuciones fiscales o parafiscales. La Ley, las Ordenanzas y los Acuerdos deben fijar, directamente, los sujetos activos y pasivos, los hechos y las bases gravables, y las tarifas de los impuestos. La ley, las ordenanzas y los acuerdos pueden permitir que las autoridades fijen la tarifa de las tasas y contribuciones que cobren a los contribuyentes, como recuperación de los costos de los servicios que les presten o participación en los beneficios que le proporcionen; pero el sistema y método para definir tales costos y beneficios, y la forma de hacer su reparto, deben ser fijados por la ley, las ordenanzas o los acuerdos. Las leyes, ordenanzas o acuerdos que regulen contribuciones en las que la base sea el resultado de hechos ocurridos durante un período que comience después de iniciar la vigencia de la respectiva ley, ordenanza o acuerdo".

21 Ver Corte Constitucional de Colombia. Sentencia C- 222 de 1995. (M.P. José Gregorio Hernández: Mayo 18 de 1995). "La atribución de legislar en materia tributaria, principalmente encomendada al Congreso de la República, es lo bastante amplia y discrecional como para permitirle fijar los elementos básicos de cada gravamen atendiendo a una política tributaria que el mismo legislador señala, siguiendo su propia evaluación, 
Con base en el principio de autonomía tributaria, las entidades territoriales gozan de potestad de autoadministrar y autofinanciar sus intereses por medio de unos recursos propios conferidos por la constitución, aclarando que ello no indica independencia absoluta de parte de las entidades territoriales. La Constitución establece la conservación de esa unidad y por tanto depende de lo establecido a nivel central. ${ }^{22}$

El artículo 338 Superior en su inciso segundo establece que la ley, las ordenanzas y los acuerdos podrán permitir que las autoridades fijen la tarifa de las tasas y contribuciones ${ }^{23}$ que cobren a los contribuyentes, como recuperación de los costos de los servicios que les presten o la participación en los beneficios que les propor-

sus criterios y sus orientaciones en torno a las mejores conveniencias de la economía y de la actividad estatal. Así, mientras las normas que al respecto establezca no se opongan a los mandatos constitucionales, debe reconocerse como principio el de la autonomía legislativa para crear, modificar y eliminar impuestos, tasas y contribuciones nacionales, así como para regular todo lo pertinente al tiempo de su vigencia, los sujetos activos y pasivos, los hechos y las bases gravables, las tarifas y las formas de cobro y recaudo".

22 Ver Corte Constitucional de Colombia. Sentencia C-533 del 2005. (M.P. Álvaro Tafur Galvis: Mayo 24 del 2005)/ "La Corporación ha precisado que el principio de autonomía debe considerarse dentro de los límites de la Constitución y la ley, con lo que se reconoce la superioridad de las regulaciones del Estado unitario, pero en el entendido [de] que la normatividad nacional debe respetar el contenido esencial de la autonomía territorial, "que se constituye en el reducto mínimo que, en todo caso, debe ser respetado por el legislador". De esa manera se afirman los intereses locales y se reconoce la supremacía de un ordenamiento superior con lo cual la autonomía de las entidades territoriales no se configura como poder soberano sino que se explica en un contexto unitario. La garantía de esa autonomía de las entidades territoriales se concreta a través de un contenido básico que debe ser defendido por toda autoridad pública y muy especialmente en el ejercicio de la potestad legislativa. Dicho contenido está configurado por unos derechos mínimos reconocidos a esas entidades para gobernarse por autoridades propias, ejercer las competencias que les correspondan, administrar sus recursos y establecer los tributos necesarios para el cumplimiento de sus funciones, así como para participar en las rentas nacionales (art. $287 \mathrm{CP}$ )".

23 Ver Consejo de Estado. Sala de lo Contencioso/Administrativo. Sección Cuarta. Radicación número: 2006-00404. (C.P. Martha Teresa Briceño de Valencia: Julio 9 del 2009). "Dentro de ese contexto, la referencia a la obligación de señalar en el acto creador del impuesto los elementos esenciales de la obligación tributaria ha de entenderse hecha, según el tipo de gravamen, por el nivel territorial al que corresponda, de lo cual se infiere que si el legislador, como puede hacerlo (artículos 295, 3004 y $313-4$ ), decide regular o establecer normas generales sobre tributos del orden departamental, municipal o distrital, no se le puede exigir, ni debe permitírsele, que en la ley respectiva incluya directamente todos los componentes del tributo (hecho gravable, base gravable, sujetos activos, sujetos pasivos y tarifas) o, en los casos de tasas y contribuciones, el método y el sistema para recuperación de costos o la participación en beneficios - como sí está obligado a hacerlo tratándose de tributos nacionales-, pues su función no es, ni puede ser, según las reglas de la descentralización y la autonomía de las entidades territoriales, la de sustituir a los órganos de éstas en el ejercicio de la competencia que les ha sido asignada por la Constitución". cionen; pero el sistema y método ${ }^{24}$ para definir tales costos y beneficios, y la forma de hacer su reparto, deben ser fijados por la ley, las ordenanzas o los acuerdos.

La Constitución Política en su artículo 338 dejó un vacío referente a la definición del sistema y método delegándole esa atribución a la Corte Constitucional que al respecto manifestó que el sistema lo constituye una totalidad dinámica entre sus partes, teniendo entre ellos una coherencia para relacionar todos los componentes en un conjunto en el que el sistema tributario combina unas reglas y unos preceptos para determinar los costos y los beneficios que ocasiona una obra o servicio prestado y hace su distribución. Mientras que el método constituye el procedimiento que deben seguir para hacer efectivo el cumplimiento de la obligación tributaria. ${ }^{25}$

Asimismo, la Carta Constitucional de 1991 no fue clara al referirse a cuál sería el método para establecer el sistema y método y quiénes serían las autoridades competentes [para ello, al respecto, la Corte ha sostenido posturas diferentes: la primera consiste en que el sistema y método se puede fijar por medio de unos principios tributarios (equidad, eficiencia y progresividad) que permitan guiar a las autoridades administrativas para establecer la tarifa del costo de los servicios. Con esta postura, la Corte adoptó un criterio flexible al determinar que la ley no puede ser arbitraria en describir

24 Ver Corte Constitucional de Colombia. Sentencia C-950 del 2007. (M.P. Manuel José Cepeda Espinoza: Noviembre 14 del 2007). "La jurisprudencia constitucional ha considerado "[...] que tanto el 'sistema' como el 'método', referidos en el artículo 338 de la Constitución, deben ser lo suficientemente claros y precisos a fin de evitar que los órganos de representación popular desatiendan un expreso mandato Superior, mas no por ello tienen que hacer una descripción detallada o rigurosa de cada uno de los elementos y procedimientos a tener en cuenta para fijar la tarifa, pues en tal caso la facultad constitucional de las autoridades administrativas perdería por completo su razón de ser. Se trata, si se quiere, de una suerte de competencias compartidas, donde el Congreso, las asambleas y los concejos son los encargados de señalar los elementos estructurales del método y del sistema tarifario, mientras que a las autoridades administrativas corresponde desarrollar los parámetros previamente indicados".

25 Ver Corte Constitucional de Colombia. Sentencia C-243 del 2005. (M.P. Álvaro Tafur Galvis: Marzo 17 del 2005). “[...] En efecto, un sistema "se define por el hecho de no ser un simple agregado desordenado de elementos sino por constituir una totalidad, caracterizada por una determinada articulación dinámica entre sus partes". Supone coherencia interna para relacionar entre sí los componentes de un conjunto, que en el ámbito tributario representan la combinación de reglas y directrices necesarias para determinar los costos y beneficios de una obra o servicio, así como la forma de hacer su distribución.

Por su parte, el método está referido a los pasos o pautas que deben observarse para que los componentes del sistema se proyecten extrínsecamente. Así, constituye el procedimiento a seguir con el objeto de determinar en concreto el monto de la obligación tributaria. 
un sinnúmero de recomendaciones y para el caso de las tasas y contribuciones desbordaría la atribución otorgada por la Carta Constitucional en su artículo 338 al permitir que las autoridades administrativas sean las que fijen el costo de las tarifas.

Con esta postura, ${ }^{26}$ las autoridades administrativas pueden realizar dicha atribución con sujeción de los principios del sistema tributario tales como los de equidad, eficiencia y progresividad consagrados en el artículo 363 de la Carta Constitucional. Manteniendo esta postura, en Sentencia C-482 de 1996, aduce que la ley ${ }^{27}$ no tiene por qué contener una serie de procedimientos para que las autoridades administrativas establezcan el costo de las tarifas a cobrar por las tasas o contribuciones porque con ello serían inocuas las atribuciones que le otorgó la Carta Constitucional en su artículo 338. La hacienda pública moderna está regida por un sistema tributario que se encuentra consagrado en el artículo 363 de la Constitución Política orientando con ello la actuación de las autoridades administrativas. Sostener la tesis del artículo 338 Superior haría un marco inocuo y lesivo para la competencia asignada a las autoridades administrativas que en últimas ellas son las que tiene que establecer el costo de los servicios que prestan. Finalmente, los actos que con motivo de la delegación que otorgó el artículo 338 para la recuperación de los costos de las tarifas se encuentran sujetos a control por parte de la jurisdicción de lo contencioso-administrativo.

En este fallo, los magistrados Jorge Arango Mejía y Antonio Barrera Carbonell dan su salvamento de voto ${ }^{28}$

26 Ver Corte Constitucional de Colombia. Sentencia C-144 de 1993. (M.P. Eduardo Cifuentes Muñoz: Abril 20 de 1993). "[...] la determinación legal del sistema y método para definir el costo de un servicio, solo puede juzgarse en cada caso concreto y tomando en consideración las modalidades peculiares del mismo.

[...] El legislador, en lo concierne a este aspecto, optó por el sistema proporcional como se infiere el texto de la norma. En efecto, la relación directa que debe existir entre el monto global de las tasas y los costos recuperables, obliga a la autoridad a obtener valores unitarios que traduzcan dichos costos en relación con cada tipo de servicio prestado que, en consecuencia, tendrá una tarifa uniforme que se cancelará en cada ocasión que se solicite el servicio".

27 Ver Corte Constitucional de Colombia. Sentencia C-482 de 1996. (M.P. Jorge Arango Mejía y Hernando Herrera Vergara: Septiembre 26 de 1996). "[...] no es necesario que las leyes previstas en el inciso segundo del artículo 338, usen las palabras "sistema" y "método", como si se tratara de fórmulas sacramentales. Basta que de su contenido se deduzcan el uno y el otro, es decir, los principios que deben respetar las autoridades y las reglas generales a que están sujetas, al definir los costos recuperables y las tarifas correspondientes".

28 Ídem. Salvamento de voto. "En esos términos, una interpretación coherente de la normatividad constitucional y el fin del precepto superior, argumentando que las leyes, las ordenanzas y los acuerdos deben facultar a las autoridades administrativas a través de un Acto mediante el cual autorice señalar el sistema y método y defina los costos y las formas en que va a hacer su reparto y no rebosar la competencia atribuida a los funcionarios de la rama ejecutiva.

En sentencia de $1994^{29}$ la Corte consagra que el establecimiento del sistema y método deben estar enmarcados dentro de "los principios de legalidad y reserva de la ley; el tributo, sus elementos y el sistema y método deben estar previamente establecidos en una norma", como pautas importantes para el contribuyente y para las autoridades administrativas que fijen la tarifa para la recuperación de los costos como recuperación de los servicios que se prestan, constituyendo con ellos garantía fundamental establecida por la Carta Constitucional.

En fallo de 1996, la Corte adopta una postura flexible en la que aduce que para establecer el sistema y método el legislador ${ }^{30}$ no tiene que hacerlo mediante expresiones aritméticas o fórmulas exactas, sino que las leyes, las ordenanzas y los acuerdos deben recoger hipótesis normativas para establecer la tarifa de las tasas $y$ las contribuciones por los servicios prestados, asignándoles a las autoridades administrativas un poder tributario derivado.

llevan a la conclusión según la cual los métodos - pautas técnicas encaminadas a la previa definición de los criterios que tienen relevancia en materia de tasas y contribuciones para determinar los costos y beneficios que inciden en una tarifa - y los sistemas - formas específicas de medición económica, de valoración y ponderación de los distintos factores que convergen en dicha determinación - son directrices cuyo acatamiento es obligatorio para el encargado de fijar la tarifa y constituyen a la vez garantía del contribuyente frente a la administración".

29 Ver Corte Constitucional de Colombia. Sentencia C-545 de 1994. (M.P. Fabio Morón Díaz: Diciembre 1 de 1994). “Tan importante es en la norma que nos ocupa la posibilidad de que mediante ley, ordenanza o acuerdo se faculte a determinada autoridad para fijar las tarifas de tasas o contribuciones como lo son los requisitos constitucionales en cuyo desarrollo el respectivo acto de autorización debe señalar el sistema y método para definir los costos que se busca recuperar mediante el tributo y los beneficios en los que habrá de participar el contribuyente como factores indispensables para la señalada fijación, así como la forma de hacer el reparto de aquéllos elementos”.

30 Ver Corte Constitucional de Colombia. Sentencia C-495 de 1996. (M.P. Fabio Morón Díaz: Septiembre 26 de 1996). "La consagración de un método y un sistema no significa necesariamente la expresión aritmética o numérica mediante fórmulas exactas, sino que mediante la ley, ordenanzas y acuerdos se recojan también hipótesis normativas mediante las cuales se puedan definir los costos y beneficios que fijen la tarifa como recuperación de los costos que les presenten o participación en los beneficios que les proporcionen las autoridades administrativas competentes en materia de ingresos públicos, de forma que las autoridades administrativas pueden ejercer excepcionalmente un poder tributario derivado de las tasas o contribuciones, en forma precaria y limitada”. 
En el 2003, la Corte Constitucional ${ }^{31}$ manifiesta que no se trata de que el legislador establezca unas formulas sacramentales, "sino de unos lineamientos que guíen a las autoridades administrativas con el fin de que puedan establecer el sistema y método".

La tercera posición adoptada por la jurisprudencia Constitucional trata de un criterio riguroso en el cual establece que el sistema y método debe ser fijado por la ley, el acuerdo y la ordenanza, de acuerdo con una sana interpretación del inciso segundo del artículo 338 establece que el "sistema y método debe estar contemplado en las leyes, ordenanzas y acuerdos los cuales son emitidos por los órganos de representación popular, significando con ello que el sistema y método debe ser establecido por los entes de representación popular". En Sentencia C-465 de 1993, ${ }^{32}$ dice que el sistema y método debe estar inmersos en las normas, respecto del presente caso en las normas presupuestales.

En salvamento de voto de los magistrados Antonio Barrera Carbonell y Jorge Arango Mejía, manifies$\tan$ que el artículo 338 Superior establece unos factores consistentes en la "separación de competencias", la primera consiste en la determinación del método o el sistema para definir el costo por parte del legislador, y segundo la competencia que tienen las autoridades administrativas de cobrar los costos de acuerdo con el método y el sistema establecido por el legislador. ${ }^{33}$

31 Ver Corte Constitucional de Colombia. Sentencia C-816 del 2003. (M.P. José Gregorio Hernández Galindo: Octubre 20 del 2003). "No se trata de fórmulas sacramentales ni de simples denominaciones, sino de linderos sustanciales de la atribución que se otorga a las autoridades administrativas. En consecuencia, bien pueden encontrarse fijados en la norma el método y el sistema sin nombrarlos, o por el contrario estar mencionados y materialmente no hallarse contenidos en el precepto. Será el Juez Constitucional el encargado de verificar si su contenido corresponde o no a la exigencia plasmada en la Carta Política, según que se consagre una atribución técnicamente reglada o que se conceda una autorización para obrar arbitrariamente".

32 Ver Corte Constitucional de Colombia. Sentencia C-465 de 1993. (M.P. Vladimiro Naranjo Meza: Octubre 21 de 1993). "La Constitución en su artículo 338, inciso 2o. ordena que la ley, la ordenanza o el acuerdo que permita que las autoridades fijen la tarifa de las tasas y contribuciones, deben definir previamente tres elementos: a) un sistema, b) un método para definir costos y beneficios, y c) una forma para hacer el reparto entre los beneficiarios del servicio.

33 Ídem. "Obsérvese en apoyo de esta tesis que la Constitución habla de "ley, ordenanza o acuerdo". Y leyes, ordenanzas o acuerdos sólo dictan, respectivamente, el Congreso, las Asambleas y los Cabildos. Por esta razón, "no les es dado a tales corporaciones conferir facultades a autoridades de la rama ejecutiva para cumplir la función que la Constitución les atribuye exclusivamente a ellas".

Recuérdese, además, que el Presidente no dicta leyes, ni el Gobernador ordenanzas, ni el Alcalde acuerdos. Y que la concesión de facultades en este caso es improcedente por la misma razón que para decretar impuestos (inciso tercero, numeral 10, artículo 150 de la Constitución)".
En Sentencia C-455 de 1994, la Corte Constitucional $^{34}$ al respecto dice que los entes colegiados de representación popular se encuentran facultados para establecer los tributos y sus elementos que la componen pero excepcionalmente bajo el artículo 338 constitucional la ley, ordenanzas y acuerdos pueden permitir que las autoridades administrativas fijen las tarifas de las tasas y contribuciones "pero el sistema y método debe estar previamente establecido en la ley, ordenanzas y los acuerdos". La única oportunidad legal que otorga la Constitución a las autoridades administrativas es la de establecer la tarifa de acuerdo con el sistema y método fijado por las leyes como recuperación de los costos por los servicios prestados. En Sentencia C-252 de 1997 dice que "el sistema y método debe estar contemplado en las leyes a través de los principios democráticos como son los entes de elección popular, Congreso, Asamblea y Concejos". En Sentencia 1067 del 2002,, ${ }^{35}$ establece en el inciso segundo del artículo 338 C.N. es claro en otorgar ciertas facultades a las autoridades administrativas para que establezcan los costos de las tarifas de las tasas y contribuciones con una indicación de que el sistema y método "son reglados y no discrecionales" por tanto deben ser establecidos por la ley.

Teniendo en cuenta el principio de legalidad de los tributos, ${ }^{36}$ en sentencia del 2009 establece que tanto

34 Ver Corte Constitucional de Colombia. Sentencia C-455 de 1994 (M.P José Gregorio Hernández Galindo: Octubre 20 de 1994). "Dentro de la filosofía que inspira la normatividad constitucional al respecto, no hubiera podido entenderse que la atribución de competencia para la fijación de tarifas de tasas y contribuciones implicara la transferencia de un poder absoluto e ilimitado a manos de las autoridades encargadas de prestar los servicios, facultadas a la vez para su percepción y cobro y claramente interesadas en la captación de recursos por esta vía.

En consecuencia, el constituyente tuvo buen cuidado en determinar que el sistema y método para definir los expresados costos y beneficios, con base en los cuales habrán de ser fijadas las tarifas, así como la forma hacer su reparto, deben ser fijados por la ley, las ordenanzas o los acuerdos".

35 Ver Corte Constitucional de Colombia. Sentencia C-1067 del 2002 (M.P. Jaime Córdoba Triviño: Marzo 12 del 2002). "De acuerdo con el principio democrático que rige nuestro Estado social de derecho, en tiempo de paz el Congreso, las asambleas y los concejos son los únicos que están facultados para establecer las bases de los impuestos, es decir para fijar todos los elementos de la obligación tributaria, incluida la tarifa. Se reitera que en materia de tasas y contribuciones, la Carta Política dispone que la regla anterior se debe observar, excepto en lo correspondiente a las tarifas, pues tratándose de estos gravámenes, la ley, las ordenanzas y los acuerdos pueden permitir que las mismas sean fijadas por las autoridades, pero siempre $-\mathrm{y}$ es una condición sine qua non- que el sistema y método para definir los costos y beneficios y la forma de hacer su reparto, sean fijados por las corporaciones de elección popular. Esta fue una concesión que dentro del sistema democrático se hizo a las autoridades, pues deja en manos de otros la determinación de la tarifa.

36 Ver Corte Constitucional de Colombia. Sentencia C-134 del 2009. (M.P. Mauricio González Cuervo: Febrero 25 del 2009). "Por excepción, 
los tributos como el sistema y método deben estar contemplados en la ley. Asimismo lo sostiene la sentencia C-594 del 2010, en la que manifiesta que el artículo 338 Constitucional en su inciso segundo le concede unas facultades a las autoridades administrativas de fijación de la tarifa de las tasas y contribuciones pero "el sistema y método deben estar contemplados en la Ley, Ordenanza Departamental y Acuerdo Municipal". ${ }^{37}$

En Sentencia C-704 del 2010, de acuerdo con los principios legales, tales como el principio de legalidad y predeterminación de los tributos - según el cual "el Congreso, Asambleas Departamentales y Concejos Municipales le corresponde establecer los tributos tales como los impuestos, tasas y contribuciones, definir los elementos en la ley, ordenanza y acuerdos municipales; pero tratándose de tasas y contribuciones su obligación no solo se encuentra limitada en la fijación de las tarifas sino que también debe establecer el sistema y método para establecerlas", ${ }^{38}$ al principio de reserva de la ley, al Congreso de la República, a las asambleas departamentales y a los concejos municipales les corresponde "establecer el sistema y método", con el fin de que las autoridades administrativas puedan fijar la tarifa de las tasas y contribuciones y así evitar arbitrariedades por

tratándose de tasas y contribuciones, el elemento "tarifa" de estos tributos puede ser definido por la autoridad administrativa. El inciso 2 del artículo 338 dice que "La ley, las ordenanzas y los acuerdos pueden permitir que las autoridades fijen la tarifa de las tasas y contribuciones que cobren a los contribuyentes, como recuperación de los costos de los servicios que les presten o participación en los beneficios que les proporcionen [...]".

Tal habilitación constitucional al Ejecutivo tiene un marco legal para su ejercicio al precisar enseguida que "[...] el sistema y método para definir tales costos y beneficios, y la forma de hacer su reparto, deben ser fijados por la ley, las ordenanzas o los acuerdos [...]".

37 Ver Corte Constitucional de Colombia. Sentencia C- 594 del 2010. (M.P. Luis Ernesto Vargas Silva: Julio 27 del 2010): "la norma constitucional, además de enunciar el principio de reserva legal en materia fiscal, objeto de posterior desarrollo, consagra el de legalidad tributaria que preside la creación de los gravámenes. En este sentido estipula que "la ley, las ordenanzas y los acuerdos deben fijar, directamente, los sujetos activos y pasivos, los hechos y bases gravables, y las tarifas de los impuestos". Solo excepcionalmente, respecto de la tarifa de las tasas y contribuciones, este mismo artículo de la Carta autoriza que la competencia para fijarla sea atribuida a otras autoridades, siempre que en la ley, la ordenanza o el acuerdo respectivo, se fije el sistema y método para determinarla". 38 Ver Corte Constitucional de Colombia. Sentencia C-704 del 2010. (M.P. María Victoria Calle: Septiembre 6 del 2010): “[...] el principio de legalidad tiene el sentido de una orden, dirigida a los órganos de representación popular facultados para establecer las contribuciones fiscales y parafiscales, enderezada a garantizar que todo acto de imposición predetermine debidamente los elementos mínimos de la obligación tributaria. Esta orden sufre una variación en sus alcances materiales, dependiendo de la especie tributaria que pretenda crearse. En general, en el Constitucionalismo Colombiano se han identificado tres clases de gravámenes: los impuestos, las tasas y las contribuciones". parte de la autoridad administrativa. ${ }^{39}$ El principio de certeza del tributo consagra que la norma que establece el tributo debe ser clara, con el sistema y método para fijar el monto de las tarifas del sistema y método para definir el costo de las tarifas de las tasas y contribuciones exigencia que

[...] solo admite como excepción, la posibilidad de que la ley permita a las autoridades administrativas fijar la tarifa de las tasas y contribuciones, siempre y cuando en los mismos actos se haya previsto el sistema y método para establecer los costos y los beneficios de los que depende la tarifa. ${ }^{40}$ (Cursivas fuera de texto).

Finalmente, la Corte mantiene otra postura: se trata de un concepto intermedio según el cual la Corte manifiesta que tanto los entes de representación popular (Congreso, asambleas departamentales y concejos municipales) deben compartir la competencia establecida en la Carta Constitucional y así mismo armonizar los preceptos al efecto útil de las normas.

Esta postura tuvo sus inicios en la Sentencia C-1371 del 2000 aduce al respecto que la Carta Constitucional de 1991 el principio de legalidad tributaria concedió el poder de legislar al Congreso de la República, pero este

39 Ver Corte Constitucional de Colombia. Sentencia C-220 del 2011. (M.P. Jorge Ignacio Pretelt: Marzo 29 del 2011): “[...] el principio de legalidad tiene el sentido de una orden, dirigida a los órganos de representación popular facultados para establecer las contribuciones fiscales y parafiscales, enderezada a garantizar que todo acto de imposición predetermine debidamente los elementos mínimos de la obligación tributaria. Esta orden sufre una variación en sus alcances materiales, dependiendo de la especie tributaria que pretenda crearse. En general, en el Constitucionalismo colombiano se han identificado tres clases de gravámenes: los impuestos, las tasas y las contribuciones. La Constitución, en su artículo 338, dispone que la ley, las ordenanzas y los acuerdos deben fijar "directamente" los sujetos activos y pasivos, los hechos y las bases gravables de todos los tributos, y además "las tarifas de los impuestos". En cambio, cuando se trata de tasas o de contribuciones, dice la Constitución, "[1]a ley, las ordenanzas y los acuerdos pueden permitir que las autoridades fijen la tarifa $[\ldots]$ que cobren a los contribuyentes, como recuperación de los costos de los servicios que les presten o participación en los beneficios que les proporcionen", siempre y cuando el correspondiente acto de creación tributaria establezca "el sistema y método para definir tales costos y beneficios, y la forma de hacer su reparto". La jurisprudencia de esta Corte ha interpretado, en ese contexto, que sólo cuando se trata de impuestos, y si ese es el cometido del órgano de representación popular pluralista, y deliberativo, es obligación de quien crea el tributo fijar directamente la tarifa con los elementos inherentes a la misma. Por lo mismo, cuando la normatividad se refiera a tasas y contribuciones, la obligación de los órganos populares pluralistas no se extiende hasta la fijación precisa y clara de la tarifa, sino hasta la determinación del sistema y método, en virtud de los cuales otras autoridades habrán de fijar la tarifa de esas especies tributarias".

40 Ver Corte Constitucional de Colombia. Sentencia C-198 del 2012. (M.P. Nilson Pinilla: Marzo 14 del 2012). 
poder no fue absoluto sino que también otorgó dichas facultades a las asambleas departamentales y los concejos municipales a través de las ordenanzas departamentales y los acuerdos municipales, deben establecer los elementos del tributo.

No obstante, el inciso segundo del artículo 338 les concede unas facultades excepcionales a las autoridades administrativas, tales como fijar el costo de la tarifa de acuerdo con un método y un sistema ${ }^{41}$ teniendo en cuenta unos procedimientos específicos acordes con la modalidad del servicio, pero sin necesidad de quebrantar o infringir dichas competencias atribuidas por la Constitución. Este fallo buscó armonizar lo consagrado en el artículo 338 constitucional al aducir que dicho artículo debe ser interpretado al efecto útil de las normas, señalando tres momentos en los cuales se debía acudir a ellos:

1. Definir los costos para conocer los gastos por la prestación de servicio.

2. Los beneficios por la prestación del servicio.

3. Identificar la forma de hacer su reparto entre los contribuyentes.

La postura anterior fue adoptada por la Sentencia C-1063 del 2003.

Es importante que los cuerpos de elección popular y las autoridades administrativas compartan sus competencias y tengan en cuenta el mandato expreso que les ha conferido el artículo 338 de la Carta Constitucional. A los entes de elección popular (el Congreso, la asamblea y los concejos) definan unos lineamientos para que las autoridades administrativas establezcan los costos de las tarifas por las tasas y contribuciones sin desbordar las competencias asignadas por la Constitución, pues ello sería inconstitucional.

En fallo del 2003, Sentencia C-155, la Corte al respecto manifestó que si bien el sistema y método se encuentra estipulado en el artículo 338 Superior, deben ser suficientemente claros para que los órganos de representación popular (Congreso, asambleas y conce-

41 Ver Corte Constitucional de Colombia. Sentencia C-1371 del 2000. (M.P. Álvaro Tafur Galvis: Octubre 11 del 2000): “[...] el señalamiento de los elementos y procedimientos que permitirán fijar los costos y definir las tarifas no requiere de una regulación detallada y rígida, pues se estaría desconociendo la delegación misma autorizada a las autoridades administrativas en el artículo 338 superior, antes citado. Así, ese señalamiento legal deberá hacerse desde una perspectiva general y amplia, ajustada a la naturaleza específica y a las modalidades propias del servicio del cual se trate". jos) no desatiendan el mandato Superior. Por eso es importante resaltar que no se requiere realizar procedimientos y fórmulas para que las autoridades administrativas fijen la tarifa, pues con ello se estaría violando una atribución conferida por la Carta Constitucional.

Los órganos de representación popular (Congreso, asamblea departamental y concejo municipal) y las autoridades administrativas deben compartir sus competencias trabajando armónicamente, de manera que los primeros (Congreso, asambleas y concejos) deben establecer los elementos necesarios del tributo y los segundos desarrollen unos parámetros para hacer efectivo su cobro.

En posterior fallo del 2003, la Corte sostuvo que el legislador omitió fijar el sistema y método, ${ }^{42} \mathrm{y}$ por tanto no podía delegar esas atribuciones a ninguna autoridad administrativa del orden nacional.

Según la Sala, el "criterio de sostenibilidad" 43 señalado en la Ley 769 del 2002 en su artículo 9- no constituye la base para ser interpretado como un sistema y método para establecer el costo de la tarifa, pues en ella no se señalan factores de medición económica ni de ponderación, pues ello no es suficiente para guiar a las autoridades administrativas para establecer el costo de las tarifas de las tasas y contribuciones. El artículo 338 de la Carta Constitucional, en su inciso segundo, indica que el sistema y método y la forma de hacer su reparto debe se ser fijado a través de la ley, las ordenan-

\footnotetext{
42 Ver Corte Constitucional de Colombia. Sentencia C-525 del 2003. (M.P. Manuel José Cepeda Espinosa: Julio 1 del 2003). "No sucede lo mismo frente a las entidades territoriales, porque como se trata de una competencia compartida entre el Congreso y los diferentes órganos de representación popular, las asambleas departamentales o los concejos municipales, según el caso, pueden (en este caso deben) señalar el sistema y método para fijar la tarifa, estando facultados incluso para concretarla directamente en situaciones específicas.

Según fue explicado, frente a las entidades territoriales el Decreto 1604 de 1966 constituye una norma habilitante para fijar la contribución a nivel local. Por tal motivo, el sistema y método deben ser señalados por las asambleas departamentales o los concejos distritales y municipales, pues de lo contrario ninguna autoridad administrativa estará autorizada para fijar el gravamen, so pena de vulnerar el principio de legalidad tributaria". 43 Ver Corte Constitucional de Colombia. Sentencia C- 532 del 2003. (M.P. Manuel José Cepeda Espinosa: Julio 3 del 2003): "Ello porque como ya se señaló en la Sentencia C-455 de 1994, reiterada por las Sentencias C-816 de 1999, C-1371 del 2000 y C-155 del 2003, el método y el sistema hacen referencia a criterios técnicos y formas de medición económica y de ponderación de factores, que indiquen claramente la forma de calcular la tarifa. El simple criterio de "sostenibilidad", prima facie, no indica cómo, ni de qué manera, ni con base en qué valores o pautas debe fijarse el monto de las tarifas, de tal forma que no es suficiente para señalar que el legislador cumplió con el deber constitucional de indicar en la ley, el "método" y el "sistema" para la determinación de las tarifas que autorizó fijar al Ministerio de Transporte."
} 
zas y los acuerdos y no limitarse con la simple remisión al artículo 363 constitucional en el que se consagran los principios del sistema tributario, tales como el de equidad, eficiencia y progresividad, con el fin de que se pueda dar cumplimiento a la exigencia contemplada en el artículo constitucional antes mencionado, por cuanto dichos principios no guían a la autoridad administrativa para la fijación del costo de la tarifa, conllevando con ello a delegar dichas facultades a las autoridades administrativas.

En la Sentencia C-243 del 2005, la Honorable Corte Constitucional manifiesta que en el artículo $338 \mathrm{Su}$ perior, en su inciso segundo, debe interpretarse de acuerdo con el efecto útil de las normas, mientras que la Sentencia C-155 del 2003 propone que deben existir unas competencias compartidas entre las autoridades administrativas y los cuerpos de elección popular, pues los últimos deben fijar el sistema y método sin necesidad de establecer un sinnúmero de fórmulas, sólo basta que de ella se deduzcan a través de unas reglas, procedimientos y principios y no dejar esta atribución en manos de las autoridades administrativas, pues sería ir en contra de lo establecido en la Carta Constitucional.

Dicha teoría de la "competencia compartida" de acuerdo con el artículo 338 constitucional se puede deducir que el legislador no requiere desarrollar unas normas sacramentales o una descripción detallada, sino que basta con la enunciación de unos principios que las autoridades administrativas deban respetar con el fin de establecer el costo de las tarifas por la prestación de los servicios.

\section{CONCLUSIONES}

La Constitución de 1991 le confirió competencia del poder legislativo al Congreso (Art. 150), pero el artículo 338 constitucional otorga un poder derivado a las asambleas departamentales y los concejos municipales para establecer los tributos en su jurisdicción. Igualmente confiere unas prerrogativas a las autoridades administrativas para fijar el monto de las tarifas, y establecer el costo de las tarifas de las tasas y contribuciones.

La Constitución de 1991 deja un vacío respecto de la competencia para establecer el sistema y método, dejando en cabeza de la Corte Constitucional pronunciarse al respecto, manifestando que se trata de "competencias compartidas", y que les corresponde a los órganos de representación popular enunciarlos en la ley, la ordenanza departamental y el acuerdo municipal, y las autoridades administrativas fijarlas guiadas por medio de los principios del sistema tributario.

\section{REFERENCIAS}

Consejo de Estado. Sala de lo Contencioso-Administrativo. Sección Cuarta. Expediente 16544. (C.P. Martha Teresa Briceño de Valencia: Julio 9 del 2009).

Consejo de Estado. Sala de lo Contencioso-Administrativo. Sección Cuarta. Radicación número: 2006-00404. (C.P. Martha Teresa Briceño de Valencia: Julio 9 del 2009).

Constitución Política de Colombia. [Const.] Art. 338. Julio 7 de 1991. (Colombia).

Corte Constitucional de Colombia. Sentencia C-144 de 1993. (M.P. Eduardo Cifuentes Muñoz: Abril 20 de 1993).

Corte Constitucional de Colombia. Sentencia C-465 de 1993. (M.P. Vladimiro Naranjo Meza: Octubre 21 de 1993).

Corte Constitucional de Colombia. Sentencia C-455 de 1994. (M.P José Gregorio Hernández Galindo: Octubre 20 de 1994).

Corte Constitucional de Colombia. Sentencia C-545 de 1994. (M.P. Fabio Morón Díaz: Diciembre 1 de 1994).

Corte Constitucional de Colombia. Sentencia C-222 de 1995. (M.P. José Gregorio Hernández: Mayo 18 de 1995).

Corte Constitucional de Colombia. Sentencia C-482 de 1996. (M.P. Jorge Arango Mejía y Hernando Herrera Vergara: Septiembre 26 de 1996).

Corte Constitucional de Colombia. Sentencia C-495 de 1996. (M.P. Fabio Morón Díaz: Septiembre 26 de 1996).

Corte Constitucional de Colombia. Sentencia C-1371 del 2000. (M.P. Álvaro Tafur Galvis: Octubre 11 del 2000).

Corte Constitucional de Colombia. Sentencia C-1179 del 2001. (M.P. Jaime Córdoba Triviño: Noviembre 8 del 2001).

Corte Constitucional de Colombia. Sentencia C-1067 del 2002. (M.P. Jaime Córdoba Triviño: Marzo 12 del 2002).

Corte Constitucional de Colombia. Sentencia C-155 del 2003. (M.P. Eduardo Montealegre: Febrero 26 del 2003).

Corte Constitucional de Colombia. Sentencia C-525 del 2003. (M.P. Manuel José Cepeda Espinosa: Julio 1 del 2003).

Corte Constitucional de Colombia. Sentencia C-532 del 2003. (M.P. Manuel José Cepeda Espinosa: Julio 3 del 2003).

Corte Constitucional de Colombia. Sentencia C-816 del 2003. (M.P. José Gregorio Hernández Galindo: Octubre 20 del 2003).

Corte Constitucional de Colombia. Sentencia C-243 del 2005. (M.P. Álvaro Tafur Galvis: Marzo 17 del 2005). 
Corte Constitucional de Colombia. Sentencia C-533 del 2005. (M.P. Álvaro Tafur Galvis: Mayo 24 del 2005).

Corte Constitucional de Colombia. Sentencia C-1171 del 2005 (M.P. Álvaro Tafur Galvis: Noviembre 17 del 2005).

Corte Constitucional de Colombia. Sentencia C-950 del 2007. (M.P. Manuel José Cepeda Espinoza: Noviembre 14 del 2007).

Corte Constitucional de Colombia. Sentencia C-134 del 2009. (M.P. Mauricio González Cuervo: Febrero 25 del 2009).

Corte Constitucional de Colombia. Sentencia C-594 del 2010. (M.P. Luis Ernesto Vargas Silva: Julio 27 del 2010).

Corte Constitucional de Colombia. Sentencia C-704 del 2010. (M.P. María Victoria Calle: Septiembre 6 del 2010).

Corte Constitucional de Colombia. Sentencia C-220 del 2011. (M.P. Jorge Ignacio Pretelt: Marzo 29 del 2011).

Corte Constitucional de Colombia. Sentencia C-198 del 2012. (M.P. Nilson Pinilla: Marzo 14 del 2012).

Ernesto Eseverri. Derecho tributario. Parte general. Pág. 213. Editorial Tirant Lo Blanch. (2008).

Félix de Luis Díaz de Monasterio \& Francisco Uría Fernández. El sistema fiscal español y las entidades y operaciones financieras. Estudios en homenaje a Enrique Piñel. Pág. 76. Editorial La Ley. (2006).
Héctor B. Villegas. Curso de finanzas, derecho financiero y tributario. Vol. II. Pág. 90. Editorial Depalma. (1979).

Horacio Belsunce García. Temas de derecho tributario. Editorial Abeledo Perrot. (1982).

José Luis Zavala Ortiz. Manual de derecho tributario. Thomson Reuters. (2010).

Ley 58 del 2003. Ley General Tributaria. Diciembre 17 del 2003. (España).

Maurice Duverger \& Enrique Bagaria Perpiña. Hacienda pública. Pág. 70. Casa Editorial. (1980).

Mauricio Plazas Vega. Derecho de la hacienda pública y derecho tributario. Las ideas políticas de la hacienda pública. Pág. 870. Editorial Temis. (2000).

Ramón Valdes Costa. Curso de derecho tributario. Pág. 179. Editorial Temis. (2001).

Urias Torres Romero. Cita a la doctora Lucy Cruz de Quiñónez. En Memoria. Instituto Colombiano de Derecho Tributario. Décimas Jornadas de Derecho Tributario. Principios Constitucionales de Derecho Tributario. Pág. 10. (1989). http://repository.urosario.edu.co/bitstr eam/10336/2144/1/19075786-2010.pdf 